\title{
Boa governança territorial em pequenos municípios
}

\author{
Good territorial governance in small municipalities
}

Buena gobernanza territorial en los municipios pequenos

Rariane Rodrigues Doerl Santos

ORCID: https://orcid.org/0000-0002-2024-4163

Universidade Federal dos Vales de Jequitinhonha e Mucuri, Brasil E-mail: advdoerl@gmail.com

Ciro Meneses Santos

ORCID: https://orcid.org/0000-0001-8687-0987 Universidade Federal dos Vales de Jequitinhonha e Mucuri, Brasil E-mail: cirosantos@gmail.com

Marcio Coutinho de Souza

ORCID: https://orcid.org/0000-0002-4238-1572 Universidade Federal dos Vales de Jequitinhonha e Mucuri, Brasil E-mail: marcio.souza@ufvjm.edu.br

Raquel Cristina Lucas Mota

ORCID: https://orcid.org/0000-0003-1543-4306 Universidade Federal dos Vales do Jequitinhonha e Mucuri, Brasil E-mail: raquel.lucasmota@ufvjm.edu.br

\begin{abstract}
Resumo
O Estado como interventor, deve organizar o planejamento urbano por meio da execução de políticas públicas. Nesse contexto, a boa governança fundiária é importante para o desenvolvimento territorial equilibrado do município, visto que a inobservância do município local no que se refere ao melhor ordenamento territorial gera malhas urbanas caóticas. As cidades geralmente nascem abraçadas em seus rios e os cidadãos na busca por melhoria de vida se aglomeram em vilas, bairros e comunidades. Destarte existe a necessidade de organizar o espaço comum de todos e o Estado legisla sobre normas gerais para regulamentar o urbano das cidades. Porém, para um melhor ordenamento do solo são exigidos: interesse de agir, servidores qualificados e recursos para implementar políticas públicas eficientes e eficazes principalmente em municípios com até 20.000 habitantes onde o plano diretor não é exigido. $O$ estudo possui o objetivo de analisar as produções acadêmicas que versam sobre governança municipal a fim de identificar se a boa governança fundiária é prioridade para o gestor de pequenas cidades. Trata-se de uma revisão bibliográfica que busca realizar a análise da governança fundiária em pequenas cidades. Para uma melhor delimitação foram realizadas buscas de periódicos em revistas científicas. Como resultados no que diz respeito a boa governança territorial constatou-se que a inércia do gestor e a falta de capacidade técnica de sua equipe faz com que não seja priorizado a boa governança territorial.
\end{abstract}

Palavras-chave: Governança fundiária; Território; Planejamento urbano; Município.

\begin{abstract}
The State, as an intervener, must organize urban planning through the execution of public policies. In this context, good land governance is important for the balanced territorial development of the municipality, since the local municipality's failure to observe the best territorial planning generates chaotic urban meshes. Cities are usually born hugging their rivers, and citizens in search of a better life agglomerate in villages, neighborhoods and communities. Therefore, there is a need to organize the common space of all, and the State legislates on general rules to regulate the urbanization of cities. However, for a better land use planning it is required: interest in acting, qualified employees and resources to implement efficient and effective public policies, especially in municipalities with up to 20,000 inhabitants where the master plan is not required. The study aims to analyze the academic productions that deal with municipal governance in order to identify whether good land governance is a priority for the manager of small towns. This is a literature review that seeks to analyze land governance in small towns. For a better delimitation, searches of scientific journals were carried out. As results with respect to good territorial governance it was found that the inertia of the manager and the lack of technical capacity of his team does not prioritize good territorial governance.
\end{abstract}

Keywords: Land governance; Territory; Urban planning; Municipality.

\section{Resumen}

El Estado, como interventor, debe organizar la planificación urbana mediante la ejecución de políticas públicas. En este contexto, la buena gobernanza del suelo es importante para el desarrollo territorial equilibrado del municipio, ya que el incumplimiento de la mejor planificación territorial por parte del ayuntamiento genera mallas urbanas caóticas. 
Las ciudades suelen nacer abrazadas en sus ríos y los ciudadanos en la búsqueda de una vida mejor se aglomeran en pueblos, barrios y comunidades. Por ello, es necesario organizar el espacio común de todos y el Estado legisla sobre normas generales para regular el urbanismo de las ciudades. Sin embargo, para una mejor gestión del territorio se requiere: interés en actuar, personal cualificado y recursos para aplicar políticas públicas eficientes y eficaces, especialmente en los municipios de hasta 20.000 habitantes, donde no se requiere el plan director. El estudio pretende analizar las producciones académicas que tratan de la gobernanza municipal para identificar si la buena gobernanza del territorio es una prioridad para el gestor de las pequeñas ciudades. Se trata de una revisión bibliográfica que pretende llevar a cabo el análisis de la gobernanza de la tierra en las pequeñas ciudades. Para una mejor delimitación se realizaron búsquedas en revistas científicas. Como resultados respecto a la buena gobernanza territorial se encontró que la inercia del gerente y la falta de capacidad técnica de su equipo hace que no se priorice la buena gobernanza territorial.

Palabras clave: Gobernanza del suelo; Territorio; Planificación urbana; Municipio.

\section{Introdução}

O planejamento urbano nas cidades brasileiras tem ocupado lugar de destaque. Com o crescimento destas, surgem irregularidades fundiárias, que devem ser corrigidas, para uma melhor promoção e melhoria da mobilidade urbana, promovendo a redução do déficit habitacional dentre outras mazelas sociais, encontradas em núcleos irregulares. Além disso, é fundamental que seja colocado em pauta, além dos temas recorrentes das grandes metrópoles, o planejamento urbano em cidades de até 20.000 habitantes, que já iniciam na informalidade.

Ratificando a necessidade dos municípios de se auto-organizar, os órgãos de controle como o Tribunal de Contas da União e do Estado, têm investido em seu papel discricionário, para orientar os gestores sobre como cumprir sua função finalística, que é promover o bem comum, a segurança, o bem-estar e a justiça (Brasil, 2020 \& Brasil, 2021). Nessa perspectiva, a Governança pública é fundamental para o bom andamento da estrutura organizacional e a melhoria da qualidade de vida do cidadão, pois no momento da execução da política pública pelo município, espera-se o cumprimento de sua função direcionadora, cooperando para o processo decisório e sua efetividade.

Nesse sentido, as políticas públicas que visam conceder mais cidadania, devem ser realizadas efetivamente e as decisões dos chefes de governo devem ser claras, transparentes e publicadas para toda a sociedade. Nas últimas décadas, vários normativos foram sancionados para uma melhor organização do ordenamento urbano nas cidades. No entanto, mesmo diante do lapso temporal para uniformização, correção e implantação desses institutos, percebemos que tem sido um grande desafio para os municípios executarem estes normativos e priorizarem o planejamento urbano habitacional.

Sob o mesmo ponto de vista, observando o crescimento significativo das cidades a União foi forçada a criar o Ministério das Cidades, responsável pela elaboração da Política Nacional de Habitação (PNH), o sistema nacional de habitação de interesse social e criou o Fundo Nacional de Habitação de Interesse Social (FNHIS), com o objetivo de oferecer suporte e direcionamento aos entes da federação. Partindo dessa constatação, o presente texto propõe responder a seguinte pergunta:

\section{- A boa governança territorial é uma prioridade em pequenos municípios?}

Considerando esta inquietação, o estudo tem como objetivo analisar as produções acadêmicas que versam sobre governança municipal, a fim de identificar se a boa governança fundiária é prioridade para o gestor de pequenas cidades. Diante desse objeto de análise, sabemos que os municípios assumiram a responsabilidade de gerir seu território após a Constituição da República Federativa do Brasil (CRFB) de 1988 e dedicou um capítulo para disciplinar a política urbana. Nessa perspectiva, a Constituição Federal concedeu a estes, a possibilidade de autogestão de seu território (Brasil, 1988). Neste ponto, o estudo mostra-se relevante por tratarmos de um Estado patrimonialista em uma fase de capitalismo mundial que analisa a boa governança e utiliza algumas concepções como: avaliar, direcionar, monitorar, planejar, executar e controlar (Brasil, 2020 \& Brasil, 2021) como os gestores locais vêm priorizando o planejamento urbano habitacional.

Por fim, o artigo está organizado em mais duas seções, além desta introdução e das considerações finais. A seção dois 
Research, Society and Development, v. 10, n. 9, e33410918202, 2021

(CC BY 4.0) | ISSN 2525-3409 | DOI: http://dx.doi.org/10.33448/rsd-v10i9.18202

deste artigo pretende demonstrar a metodologia utilizada em sua elaboração. Já a seção três faz a análise das políticas públicas, políticas sociais e fontes de recursos. Por fim as considerações finais, à luz das seções anteriores, são apontamentos das questões abordadas, com contribuições à agenda de pesquisa urbana em pequenos municípios e, por último, são apresentadas as referências utilizadas no desenvolvimento do artigo.

\section{Metodologia}

O método hipotético-dedutivo, foi escolhido para elaboração da pesquisa como abordagem e orientação para o seu desenvolvimento. A técnica de pesquisa bibliográfica, forneceu o suporte ao método, para conhecer o que vem sendo publicado sobre o tema nos últimos anos. Nesse sentido, os autores (Lima \& Mioto, 2007, p. 44), afirmaram que essa "pesquisa requer alto grau de vigilância epistemológica, de observação e de cuidado na escolha e no encaminhamento dos procedimentos metodológicos $[\ldots]$ e necessitam de critérios claros" e possui uma abordagem de natureza qualitativa.

A partir desse método, o tipo de pesquisa quanto à natureza utilizado, foi aplicada; quanto aos fins, trata-se de um estudo exploratório, pois busca a coleta de dados concretos e possui definição e delineamento com planejamento flexível, por meio de pesquisa bibliográfica. Na investigação, foi utilizado o levantamento elaborado por fontes secundárias (artigos científicos), fontes primárias (leis) (Prodanov, 2013) e livros de políticas públicas.

Para a coleta de dados, foram utilizados critérios para delimitar o estudo como: a) periódicos de revistas científicas ordenados por relevância; b) critérios de inclusão, como parâmetro temático (as obras relacionadas a governança territorial), parâmetro linguístico (obras nos idiomas português e inglês) e parâmetro cronológico de publicação (onde foi definido o período a ser pesquisado, últimos dez anos 2014-2020) (Lima \& Mioto, 2007); c) critérios de exclusão, foram artigos acima de seis anos de publicação que não se referem especificamente a governança territorial, teses e dissertações.

Em sua segunda etapa, por meio de uma leitura reflexiva, foram examinados seus resumos, introduções e conclusões ou considerações finais, que apontaram questões da problemática, objetivos centrais, metodologias e resultados fundamentais de cada trabalho. Para finalizar, na terceira etapa foi realizada uma leitura aprofundada, interpretativa dos artigos selecionados com o objetivo de relacionar as ideias dos autores expressas nas obras e a sumarização dos dados coletados, para redação dos resultados.

\section{Resultados e Discussão}

Esta seção discute sobre a política pública, a política urbana, as fontes de recursos e as políticas sociais de urbanismo. O intuito desse referencial teórico é verificar se os municípios de pequeno porte priorizam a boa governança urbana.

\subsection{Política pública}

O Estado deve ser um interventor que busque a efetivação de políticas públicas (Finkler \& et al. 2020). Nesse sentido, "políticas públicas são ações que nascem do contexto social, mas que passam pela esfera estatal como uma decisão de intervenção pública, numa realidade social" (Boneti, 2018, p. 18). Assim, o Estado é representado como o agente que organiza e toma as decisões a partir de demandas específicas.

Nessa perspectiva, políticas públicas são formuladas por agentes governamentais, com legitimidade para sua implementação e execução. Estas, decorrem da atividade estatal que as elabora e planejam para a promoção e efetivação de direitos e garantias fundamentais. No momento que nos referimos aos agentes definidores de políticas públicas, especialmente de cidades e comunidades sustentáveis, fica evidente a correlação de forças internacionais no plano global que interfere nas políticas públicas nacionais devido à globalização e ao projeto mundial de produção econômica e organização política que vem 
ratificando os objetivos de desenvolvimento sustentáveis e de desenvolvimento do milênio (Boneti, 2018).

Corroborando ao entendimento, "as políticas públicas não são formadas nem executadas em ambientes passivos ou vazios, elas operam dentro de um complexo e específico contexto de instituições existentes em um determinado território" (Queiroz, 2012, p. 116). Partindo desse ideário, a formação de políticas pública é também um jogo social, com atores com poder decisório, para incluir a política pública em sua agenda de prioridade, até mesmo em ambientes democráticos, em que o planejamento, "incorpora como uma de suas habilidades a competência para defender politicamente as suas propostas de políticas públicas" (Queiroz, 2012, p. 121).

Acrescente-se que, os programas governamentais são planejados, ajustados e avaliados continuamente para verificar se a intervenção alcançou o cidadão, real beneficiário da política pública. Nessa perspectiva, o pesquisador Queiroz (2012), demonstra em seu estudo que o modelo brasileiro de planejamento, orçamento e gestão seguem quatro fases, quais sejam: formulação, execução, avaliação e reprogramação. Nesse sentido, o gestor público pode realizar a gestão de políticas públicas conforme seu planejamento e utilizar as ferramentas de gestão como: a matriz de decisão, a árvore de problemas e soluções, a análise de interesses e o marco lógico.

Logo, a primeira ferramenta é a matriz de decisão, pode ser utilizada para priorizar políticas públicas de acordo com o plano de governo. "Essa escolha que vai demonstrar a competência do governante para selecionar problemas ou compromissos, que resultem em maior impacto político positivo possível" (Queiroz, 2012, p. 169). Bem como, observância da disponibilidade financeira, urgência, importância e governança (capacidade técnica, administrativa e financeira da esfera de governo) em relação à política a ser executada.

A segunda, é a árvore de problemas, que permite uma delimitação do problema e as causas que o originaram. Nesse aspecto, o problema deve ser bem conhecido do gestor, para que seja apresentada uma política pública que corrija o problema e balize a construção de estratégias de ação a ser implementadas. Do mesmo modo, a árvore de objetivos e soluções, demonstra uma relação causa-efeito, que possibilita ao gestor uma maior clareza na definição das ações a serem realizadas (Queiroz, 2012).

A terceira ferramenta, é a análise de interesses, todos os atores buscam a satisfação de seus interesses na ação governamental. Nesse jogo social "os stakeholders, agem segundo suas preferências e interesses e pretendem influir, condicionar, bloquear ou ativas as decisões públicas utilizando de todo tipo de recursos" (Queiroz, 2012, p. 181). Deste modo, faz-se necessário a influência de atores sociais, engajados no bem-estar do cidadão, para equilibrar esse jogo social e minimizar as influências contrárias ao cidadão.

Por fim, a quarta ferramenta, é o marco lógico, quadro lógico ou "log frame", onde os objetivos de políticas públicas são apresentados sistematicamente, geralmente utilizados para a preparação, programação, execução e avaliação de políticas públicas visto que, as informações são sintetizadas e suas etapas são monitoradas continuamente para diminuir a imprecisão e aumentar a clareza dos objetivos propostos (Queiroz, 2012).

\subsection{Política Urbana}

Diante do amplo alcance do campo de políticas públicas, cabe uma melhor delimitação da mesma, para alcançar o objetivo proposto no estudo, com uma análise um pouco mais limitada, a política urbana, que tem por objetivo ordenar o pleno desenvolvimento das funções sociais da cidade e garantir o bem-estar de seus habitantes.

Nessa perspectiva, o texto da Constituição Federal de 1988 destinou todo um capítulo a política urbana, sendo que os artigos 182 e 183 transferiram a política de desenvolvimento urbano, ao poder público municipal com o objetivo de ordenar o pleno desenvolvimento das funções sociais da cidade e garantir o bem-estar de seus habitantes (Brasil, 1988). Historicamente, esse capítulo foi incorporado após muitas reivindicações pela reforma urbana e mesmo assim, a morosidade do legislativo 
somente treze anos depois foram regulados pelo Estatuto da Cidade, que determina instrumentos de política urbana para auxiliar o poder público na execução e na garantia do cumprimento da função social da propriedade (Marçal, 2020).

De igual modo, o Estatuto da cidade, disciplinou a política urbana do Brasil, em seu artigo $2^{\circ}$ estabeleceu objetivos para pleno desenvolvimento das funções sociais da cidade e da propriedade urbana, mediante as seguintes diretrizes gerais: a garantia do direito a cidades sustentáveis, entendido como o direito à terra urbana, à moradia, ao saneamento ambiental, à infraestrutura urbana, ao transporte e aos serviços públicos, ao trabalho e ao lazer, para as presentes e futuras gerações; a gestão democrática por meio da participação da população, execução e acompanhamento de planos, programas e projetos de desenvolvimento urbano; a cooperação entre os governos, a iniciativa privada e os demais setores da sociedade no processo de urbanização; o planejamento do desenvolvimento das cidades, da distribuição espacial da população e das atividades econômicas do Município e do território sob sua área de influência, de modo a evitar e corrigir as distorções do crescimento urbano e seus efeitos negativos sobre o meio ambiente; regularização fundiária e urbanização de áreas ocupadas por população de baixa renda (Brasil, 2001).

Inquestionavelmente, o Estado possui o 'poder dever' de garantir direitos dos cidadãos como moradia, saneamento, educação, segurança. Nesse sentido, mesmo com os instrumentos normativos vigentes e disponíveis para serem utilizadas pela Administração pública, ainda necessitam de efetividade, com garantia de direitos fundamentais e a cidadania exercida de forma plena, considerando o alto grau de irregularidade fundiária, de segregação espacial, exclusão social presentes nas cidades, onde as decisões são quase sempre monopolizadas e estadistas. Assim sendo, para que a população tenha uma maior participação nas decisões do gestor local a população deverá buscar uma maior participação nas decisões da coisa pública de acordo com art. 24, I da CRFB de 1988 (Silva, 2014; Brasil, 1988).

Deste modo, com o propósito de garantir direitos fundamentais, mostra-se importante a boa governança territorial na atualidade, pois a irregularidade urbanístico-fundiária é um dos fenômenos urbanos mais problemáticos do tempo presente. Esta se manifesta em quase todas as cidades brasileiras e coloca em questão não apenas o equilíbrio espacial, mas, especialmente as condições de vida de expressiva parcela da população. Com isso, fica evidente que a crescente irregularidade, advém das formas de gestão urbana adotadas historicamente pelos poderes públicos.

Ademais, a regularização fundiária urbana, possui legislação própria, a saber, a lei 13465/2017, anteriormente os municípios utilizavam o instituto de qualquer forma, ocorrendo a crescente ocupação ilegal, loteamentos clandestinos e irregulares. Considerando o caos formado, os municípios e estados passaram a realizar processos de regularização fundiária em seus territórios, buscando amenizar o crescimento desordenado da amalha urbana. Ao encontro dessa afirmação, Santos et al. (2021) mostraram que, os resultados de seus estudos apontam que a regularização fundiária urbana desenvolvida no município gera desenvolvimento local a curto, médio e longo prazo com reflexos em várias áreas.

Igualmente, os pesquisadores Pierre (1999) Bäckstrand \& et al. (2010) apud Loor, Rivadeneira \& Rivadeneira (2021 p. 6) concluíram que a gestão urbana é formada de atores com vários interesses com novos modos de governança, a saber:

A liderança da cidade envolve atores que representam não apenas o setor corporativo, mas também uma gama de interesses, como prestação de serviços, mudança climática, imigração e outros. [...] essa abordagem é consistente com os novos modos de governança, que assumem uma forma menos hierárquica e mais colaborativa e deliberativa de participação entre atores públicos e privados.

Desta maneira, nas últimas décadas surgiu a necessidade de um aprimoramento dos municípios no que se refere a gestão de políticas públicas urbanas, para amenizar o crescimento desordenado da malha urbana e desenvolvimento local. Em um contexto amplo, considera-se que, uma boa gestão territorial envolve um conjunto de atores com vários interesses e efetiva participação popular. 


\subsection{Fontes de recursos e políticas sociais de urbanismo}

Inicialmente, é visível a necessidade de reformulação de políticas públicas e implantação de programas e ações que favoreçam a todos, mesmo que alguns pesquisadores, entendam que a urbanização vem provocando degradação ambiental nas cidades com situação preocupante, no que se refere aos municípios, inclusive de pequeno porte (De Paulo, Alves \& Silva, 2014).

Nesse aspecto, é urgente à redefinição das prioridades da política urbana, por mostrar-se como uma necessidade frente às novas relações imobiliárias, aos espaços e territórios urbanos, que são potenciais de captação de recursos com capacidade de reprodução, desde que vinculados ao desenvolvimento econômico, através da formalidade de impostos urbanos arrecadados nos investimentos de infraestrutura (Campos, 2014). Portanto, para corrigir a irregularidade fundiária, é ideal a utilização do instituto da regularização fundiária.

Por outro lado, falta interesse de agir dos municípios da administração pública, por compreender que a regularização fundiária é uma despesa e não um investimento (Marçal, Portes \& Randi, 2020). Dessa forma, destaca-se a inércia do Estado, para investimentos ou implementação de programas de infraestrutura nos espaços urbanos das cidades, que integram áreas comuns a todos os cidadãos.

Por conseguinte, o coletivismo urbano, perfaz na visão dos governos um distanciamento estatal, na execução de políticas voltadas às necessidades dos espaços de assentamentos informais. O poder público na captação de investimentos para cumprimento das obrigações urbanas, passa a estabelecer articulações de governança com atores privados por meio de parcerias que trazem oportunidades ao Estado. Dessa maneira, devido à escassez de recursos públicos, parcerias são firmadas com o objetivo de que ações urbanas possibilitem uma melhor qualidade de vida aos seus cidadãos (Campos, 2014).

Inclusive, uma melhor qualidade de vida em territórios com maior desigualdade em sua estrutura espacial, dos locais de habitação, onde o poder público é principal responsável por regular e buscar soluções que minimizem problemas sociais, ambientais e urbanísticos, visto que a falta de acompanhamento por parte dos órgãos responsáveis maximiza as desigualdades (De Paulo, Alves \& Silva, 2014).

Diante dos argumentos expostos acima, a pesquisadora (Akaishi, 2011), aponta que, várias são as limitações do poder público para organizar políticas públicas urbanas, por diversos fatores. Em primeiro lugar, há um conjunto de normas que observam prioritariamente a realidade metropolitana, sem considerar que o acesso à terra regular e urbanizada são marcas das cidades brasileiras em geral. Nesse ponto, não é analisado os núcleos irregulares, formados em áreas de expansão urbana, nos pequenos municípios, sobre solo essencialmente rural, que devem inclusive ser objeto de estudo. Ademais, em municípios pequenos, não há marcos regulatórios, obrigatoriedade da elaboração de plano diretor, atendimento a sistemas financeiros formais e a omissão estatal na regulação do urbano faz com que inexistam mapas das cidades e secretarias para cadastro e controle imobiliário nas prefeituras.

Nessa perspectiva, em um segundo lugar, é verificado que o governo federal, em seu sistema de gestão e planejamento urbanos, prioriza o atendimento às regiões metropolitanas, nas quais o déficit habitacional se concentra e os pequenos municípios, não possuem prioridade e enfrentam sozinhos grandes dificuldades para conseguir apresentar projetos, contratar recursos e falta de capacidade técnica para desenvolver programas e projetos (Akaishi, 2011).

Em terceiro lugar, há a ausência de arcabouço jurídico, que trate efetivamente de territórios com tensões e conflitos cada vez maiores. As cidades como são alvos de políticas públicas, deveriam ser encaradas em suas especificidades e complexidades, bem como sua localização e região, visto que a maioria dos instrumentos urbanísticos do Estatuto da Cidade, somente se aplica em cidades de grande e médio porte, mercado de solo altamente especulativo, escassez e alto custo da terra.

Em quarto e último lugar, há uma limitada capacidade institucional, "mais obrigações e menos recursos", visto que a partir da redemocratização e com a promulgação da Constituição de 1988, novo papel foi passado aos municípios na condução 
da política urbana.

Nessa nova concepção de município atuante, a descentralização de competências aos governos locais, não foi acompanhada na diferenciação, no tratamento relacionado à desigual capacidade institucional dos municípios brasileiros e a gestão participativa induzida pela norma federal, não dialoga com a realidade local (Akaishi, 2011). Nesse sentido, a União reduz sua atuação no desenvolvimento nacional, e os poderes locais ampliam sua agenda e contraem novas responsabilidades.

Foram inúmeras as mudanças que ocorreram no mundo globalizado e os avanços legislativos são inquestionáveis. Os "municípios estão inseridos nessa teia, nesse "jogo social", o que requer dos gestores municipais que estejam atentos e atualizados quanto às mudanças, que compreendam a necessidade de novos modelos mentais, para com elas lidar e que tenham vontade de fazê-lo" (Vergara e Côrrea, 2003, p. 36). Há, portanto, uma variedade de normativos que regulamentam a expansão urbana nas cidades, no entanto, a indiferença do gestor e a incapacidade técnica de sua equipe, faz com que não haja sua aplicação e efetivação de direitos e garantias fundamentais (De Paulo, Alves \& Silva, 2014).

Para melhor exemplificar a expansão urbana e a necessidade de o gestor local priorizar o planejamento urbano, diante do estudo dos pesquisadores Matos et al. (2020), em seus resultados, demonstraram que o plano urbanístico do município de Teresina, encontra-se em conformidade com os aspectos essenciais previstos no Estatuto da Cidade. No entanto, ressalta a dificuldade da administração pública municipal na execução do previsto no normativo, considerando a complexidade e a multiplicidade de setores que devem ser envolvidos, desse modo, a ausência de ações eficazes por parte do governo local retarda seu desenvolvimento.

Por um lado, os pesquisadores Costa \& et al. (2021) analisaram as propostas de melhoria para o município de São Luís Maranhão com um plano de ação prioritário, parcerias com governo do estado e Federal e iniciativa privada com o objetivo de trazer melhorias para a cidade

Por outro lado, os autores Finkler \& et al. (2020), apontaram em seus resultados que o município de Ijui/RS, observa e prioriza programas de habitação social e busca o cumprimento do objetivo de desenvolvimento sustentável, a tornar as cidades mais humanas, inclusivas, seguras e resilientes e sustentáveis.

Já de forma complementar, a governança compreende a utilização de ferramentas no objetivo de executar políticas públicas, os pesquisadores destacam que os autores Lafferty (2006), Jon Pierre (2000), Joseph (1999), Kjær (2004) e Rhodes, (1997) apud Loor, Rivadeneira \& Rivadeneira (2021 p. 05):

A governança compreende os instrumentos e mecanismos disponíveis para direcionar uma sociedade na direção desejada. A governança é um aspecto crítico do desenvolvimento sustentável. O Objetivo de Desenvolvimento Sustentável (ODS) 17 incentiva parcerias entre o setor público, o setor privado e a sociedade civil para abordar o desenvolvimento sustentável em todas as suas escalas. A produção de governança implica que as redes de instituições e comunidades governadas de forma autônoma construam acordos para exercer poder sobre os desafios de interesse coletivo. Portanto, a governança para o desenvolvimento sustentável, requer acordos e compromissos sobre os desafios ambientais, sociais e econômicos prioritários.

Acrescente-se que Alves \& et al. (2021) realizaram um estudo que vai além da governança territorial abordando inclusive a qualidade ambiental urbana na cidade de Itajubá/MG onde existe zonas de vulnerabilidade ambiental que se compõe de forma desigual, causando danos além de urbanos, sociais e ambientais.

Diante disso, a crescente urbanização pode exigir dos gestores uma boa governança ambiental, inclusive ao referir-se a assentamentos informais, onde é necessária uma maior participação social, com atores em rede para garantir uma melhor governabilidade. 


\section{Considerações Finais}

O objetivo deste estudo foi analisar as produções acadêmicas que versam sobre governança municipal a fim de identificar, se a boa governança fundiária é prioridade para o gestor de pequenas cidades, mais especificamente na elaboração, planejamento e execução de políticas públicas de urbanismo e os recursos disponibilizados para a área. Com a construção desse objetivo surgiu a seguinte provocação “a boa governança territorial é uma prioridade em pequenos municípios? que serviu para nortear todo estudo.

No decorrer do trabalho analisamos políticas públicas, especificamente as urbanas. De modo que, os programas governamentais são planejados, ajustados e avaliados continuamente para verificar se a intervenção alcançou o cidadão, real beneficiário da política pública e que essa governança segue quatro fases, quais sejam: formulação, execução, avaliação e reprogramação e são utilizadas ferramentas de gestão como: a matriz de decisão, a árvore de problemas e soluções, a análise de interesses e o marco lógico para sua execução e avaliação. De forma um pouco mais limitada, a Constituição Federal da República, o Estatuto da Cidade e as legislações posteriores disciplinaram sobre política urbana transferindo a responsabilidade de sua execução aos municípios.

Ocorre que para garantir direitos fundamentais, mostra-se importante a boa governança territorial visto que a irregularidade urbanístico-fundiária é um dos fenômenos urbanos mais problemáticos do tempo presente. Ademais, a regularização fundiária urbana, possui legislação própria, a saber, a lei 13465/2017, anteriormente os municípios utilizavam o instituto de qualquer forma, ocorrendo a crescente ocupação ilegal, loteamentos clandestinos e irregulares. Considerando o caos formado, os municípios e estados passaram a realizar processos de regularização fundiária em seus territórios, buscando amenizar o crescimento desordenado da amalha urbana.

Analisamos também a fonte de recursos para custear as políticas públicas, sendo necessário a redefinição de prioridades em políticas urbanas. Fica demonstrado a falta interesse de agir dos municípios da administração pública, bem como um distanciamento estatal ao analisar a matéria. Quando da captação de investimentos faz-se necessário estabelecer articulações de governança para prospecção, melhores oportunidades futuras o que será possível apenas se os municípios priorizarem uma boa governança territorial.

Dessa forma, o principal intento desse artigo foi contribuir para que os gestores locais busquem uma melhor governança para que supere os obstáculos e limitações interpostos pelo governo federal, em seu sistema de gestão e planejamento urbanos, que prioriza o atendimento às grandes cidades e deixa de priorizar os pequenos municípios, a enfrentar uma limitada capacidade institucional, "mais obrigações e menos recursos", visto que a partir da redemocratização e com a promulgação da Constituição de 1988, novo papel foi passado aos municípios na condução da política urbana.

Constatamos que os direitos fundamentais e a cidadania não são exercidos de forma plena no que se refere ao planejamento urbano oferecido pelo Estado nas pequenas cidades, que nas últimas décadas surgiu a necessidade de um aprimoramento dos municípios para a gestão de políticas públicas urbanas. A partir desse exame crítico, foi constatado que a omissão do gestor e a falta de capacidade técnica de sua equipe faz com que não seja priorizado a boa gestão territorial, o planejamento urbano habitacional. Que são grandes as dificuldades para implementar instrumentos de planejamento urbano no nos municípios.

\section{Para além da conclusão, terminamos então com um indicativo para pesquisas futuras como:}

- Pesquisas sobre a exigência de plano diretor para pequenos municípios como instrumento para minimizar a irregularidade fundiária;

- Diante da ausência de recursos para custear as políticas públicas de urbanismo nos municípios, também são necessárias pesquisas sobre a boa governança territorial e a atuação gestor local; 
- Sugere-se também, pesquisa sobre a falta de equidade no que se refere a capacidade institucional dos municípios brasileiros e os normativos são direcionados prioritariamente a grandes municípios;

- Por fim, e não menos importante, podemos pesquisar como os municípios podem realizar um planejamento estratégico para execução de políticas públicas, observando as ferramentas de gestão como: a matriz de decisão, a árvore de problemas e soluções, a análise de interesses e o marco lógico.

Portanto, a contribuição final desse artigo consiste em advertir os gestores públicos, estudiosos da área de administração pública a refletirem sobre a boa governança territorial em como pode contribuir para o desenvolvimento da comunidade local garantindo direito fundamentais aos cidadãos.

\section{Referências}

Akaishi, A. G. (2011). Desafios do planejamento urbano-habitacional em pequenos municípios brasileiros. Risco Revista de Pesquisa em Arquitetura e Urbanismo (Online), (14), 41-50. https://doi.org/10.11606/issn.1984-4506.v0i14p41-50.

Alves, G. P., \& Botezeççi, L., \& Botan, M. C. C. de O., \& Anna, D. O. S. (2021). Periferização, qualidade ambiental urbana e percepção dos moradores em cidades médias: estudo de caso no município de Itajubá/MG. Research, Society and Development, (10)1, e3710111332. (CC BY 4.0). ISSN 2525-3409. DOI: http://dx.doi.org/10.33448/rsd-v10i1.11332.

Brasil. Constituição da República Federativa do Brasil de 1988. Disponível em: http://www.planalto.gov.br/ccivil_03/constituicao/constituicao.htm

Brasil. Lei Federal de n ${ }^{\circ} 10.257$ de 10 de julho de 2001. Regulamenta os arts. 182 e 183 da Constituição Federal, estabelece diretrizes gerais da política urbana e dá outras providências. Disponível em http://www.planalto.gov.br/ccivil_03/leis/leis_2001/110257.htm.

Brasil. Tribunal de Contas da União. (2020). Referencial básico de governança aplicável a organizações públicas e outros entes jurisdicionados ao TCU / Tribunal de Contas da União. Edição 3 - Brasília: TCU, Secretaria de Controle Externo.

Brasil. Tribunal de Contas da União. (2021). Dez passos para a boa governança / Tribunal de Contas da União. Edição 2 - Brasília: TCU, Secretaria de Controle Externo da Administração do Estado.

Boneti, L.W. (2007) Políticas públicas por dentro. Ijuí: Editora Unijuí. p.7-49.

Campos. Ronaldo. (2014). Política urbana e participação: construção coletiva para regularização fundiária nos espaços urbanos de domínio da união. Revista Movimentos Sociais e Dinâmicas Espaciais, Recife, (03)02.

Costa, B. S., \& Costa, S. de S., \& Batalha Junior, N. de J. P., \& Batista, C. da S. (2021). Cidades inteligentes: principais rankings e propostas de melhoria para São Luís, Maranhão. Research, Society and Development, (10)4, e47810414166. (CC BY 4.0). ISSN 2525-3409. doi:10.33448/rsd-v10i4.14166.

De Paulo, F. L. L., \& Alves, J. do A., \& Silva, S. S. DA M. (2014). Desenvolvimento urbano no município de serra talhada, Pernambuco, brasil: avaliação dos impactos sociais e ambientais provocados pelo processo de expansão urbana. Periódico Eletrônico Fórum ambiental Da Alta Paulista, 10(4). doi: 10.17271/198008271042014802.

Finkler, M. C. C., \& Silva, P. R. da., \& Mueller, A. A., \& Brizolla, M. M. B., \& Nuske, M. A., \& Zantta, J. M., \& Thesing, N. J. (2020). Habitação social como oportunidade social e a importância para o desenvolvimento do município de Ijuí/RS. Research, Society and Development, (9)12, e17891210974. (CC BY 4.0). ISSN 2525-3409. doi:10.33448/rsd-v9i12.10974.

Lima, T. C. S. DE, \& Mioto, R. C. T. (2007). Procedimentos metodológicos na construção do conhecimento científico: a pesquisa bibliográfica. Revista Katálysis, (10), esp. p. 37-45. Disponível em: https://www.scielo.br/scielo.php?pid=S1414-49802007000300004\&script=sci_arttext.

Loor, I., \& Rivandeneira, L., \& Rivadeneira. J. (2021). Gobernanza ambiental para ciudades del Sur Global: perspectivas teóricas. Research, Society and Development, (10)1, e56410112278. (CC BY 4.0). ISSN 2525-3409. doi:10.33448/rsd-v10i1.12278.

Marçal, K. M., \& Portes, M. R., \& Randi, R. D. S de S. (2020). Regularização fundiária urbana e o desenvolvimento regional. Published in: Revista Inovação Social, (2)1. pp. 33-51. https://mpra.ub.uni-muenchen.de/100806/1/MPRA_paper_100806.pdf.

Matos, K. C., \& Falcão. A. L. S., \& Lopes, W. G. R., \& Santiago, D. R., \& Sampaio, I. M. R. (2020). Importância dos planos urbanísticos e espaços livres para a sustentabilidade urbana: estudo na Cidade de Teresina, Piauí. Research, Society and Development, (9)10, e859108290. ISSN 2525-3409. doi:10.33448/rsd-v9i10.8290.

Prodanov, C. C. (2013). Metodologia do trabalho científico [recurso eletrônico]: métodos e técnicas da pesquisa e do trabalho acadêmico. - 2. ed. - Novo Hamburgo: Feevale.

Queiroz, Roosevelr Brasil. (2012). Formação e gestão de políticas públicas. Curitiba: INterSaberes. 
Research, Society and Development, v. 10, n. 9, e33410918202, 2021

(CC BY 4.0) | ISSN 2525-3409 | DOI: http://dx.doi.org/10.33448/rsd-v10i9.18202

Santos, R. R. D., \& Dias. C. A., \& Santos, A. T. O., \& Almeida. I. C., \& Santos, C. M. (2021). Urban funding regularization as a driver for increasing municipal revenue and local development, International Journal of Development Research, (11)03, pp.45782-45787. doi:10.37118/ijdr.21419.03.2021.

Silva, H. (2014). Planejamento urbano democrático como meio para o acesso ao direito à moradia. Olhares Plurais, 1(10), 62-78. Recuperado de http://revista.seune.edu.br/index.php/op/article/view/112.

Vergara, S.C., \& Correa, V.L.A. (2003). Propostas para uma Gestão Pública Municipal Efetiva. Rio de Janeiro: Editora FGV. 